\title{
Electron Tomographic Analysis of Synaptic Ultrastructure
}

\author{
Alain C. Burette ${ }^{1, *}$, Thomas Lesperance ${ }^{2}$, John Crum $^{3}$, Maryann Martone ${ }^{3,4}$, Niels \\ Volkmann ${ }^{2}$, Mark H. Ellisman ${ }^{3,4}$, and Richard J. Weinberg ${ }^{1,5}$ \\ ${ }^{1}$ Department of Cell \& Developmental Biology, University of North Carolina, Chapel Hill, North \\ Carolina, 27599 \\ 2Sanford-Burnham Medical Research Institute, La Jolla, California, 92093 \\ ${ }^{3}$ Department of Neurosciences and National Center for Microscopy and Imaging Research, \\ Center for Research in Biological Systems, University of California, San Diego, La Jolla, \\ California, 92093 \\ ${ }^{4}$ Department of Neurosciences, University of California, San Diego, La Jolla, California, 92093 \\ ${ }^{5}$ Neuroscience Center, University of North Carolina, Chapel Hill, North Carolina, 27599
}

\begin{abstract}
Synaptic function depends on interactions among sets of proteins that assemble into complex supramolecular machines. Molecular biology, electrophysiology, and live-cell imaging studies have provided tantalizing glimpses into the inner workings of the synapse, but fundamental questions remain regarding the functional organization of these "nano-machines." Electron tomography reveals the internal structure of synapses in three dimensions with exceptional spatial resolution. Here we report results from an electron tomographic study of axospinous synapses in neocortex and hippocampus of the adult rat, based on aldehyde-fixed material stabilized with tannic acid in lieu of postfixation with osmium tetroxide. Our results provide a new window into the structural basis of excitatory synaptic processing in the mammalian brain.
\end{abstract}

\section{INDEXING TERMS}

dendritic spine; synaptic vesicle; actin; PSD; active zone; exocytosis

Structure provides the basis for physiological function; this fact motivates continuing study of synaptic morphology. Excitatory synapses in the mammalian forebrain terminate mainly onto dendritic spines. Although the functional significance of their characteristic fine structure remains obscure, available evidence suggests that these synapses are highly specialized to support the short- and long-term plasticity crucial for flexible processing of information. Modern tools of cell and molecular biology have advanced our understanding of synaptic organization, but even in the current era of super-resolution light microscopy, the small size of the synapse and the dense packing of supramolecular complexes within it present a formidable challenge.

Our knowledge of the 3D organization of subcellular domains within the synapse lags far behind the rapidly accumulating data on its biochemical composition and the structure of its

(C) 2012 Wiley Periodicals, Inc.

*CORRESPONDENCE TO: Alain C. Burette, Department of Cell \& Developmental Biology, University of North Carolina, CB \# 7090, Chapel Hill, NC 27599. alain.burette@gmail.com.

Additional Supporting Information may be found in the online version of this article. 
constituent proteins. Computational modeling studies suggest that submicroscopic functional assemblies may play a crucial role in synaptic function (Collins and Grant, 2007), but the supramolecular organization of the synapse remains largely uncharted. Transmission electron microscopy (TEM) has provided a crucial tool for the elucidation of fine structure. TEM is physically capable of sub-nanometer resolution, but practical constraints make it unfeasible to prepare and examine tissue sections thinner than $\sim 40 \mathrm{~nm}$, much larger than most proteins. By generating virtual ultrathin sections, electron tomography can greatly reduce the image degradation arising from finite section thickness (Frey et al., 2006; Chen et al., 2008b; Leis et al., 2009).

TEM involves exposure of thin sections to an intense electron beam under conditions of high vacuum, requiring specialized procedures of sample preparation. Physical cryofixation, which can stabilize cells within milliseconds, provides a gold standard for the study of biological ultra-structure (Van Harreveld et al., 1974; Leis et al., 2009, Hurbain and Sachse, 2011), but cryo-electron microscopy is inherently low-contrast, and vulnerability to beam damage severely limits sample exposure. In recognition of these problems, a number of laboratories have used high-pressure freezing followed by freeze-substitution to dehydrate material and infiltrate it with plastic resin, allowing electron tomographic analysis of neuronal structure; however, technical constraints presented by the mammalian brain have limited these studies to small invertebrates, peripheral tissues, and culture systems. Electron tomographic analysis of brain continues to rely on chemical fixation with mixed aldehydes (Sosinsky et al., 2008).

Ultrastructural studies routinely use $\mathrm{OsO}_{4}$ to stabilize and contrast lipid-rich membranes. However, intense staining of the lipid bilayer can hide subtle details of membrane substructure while obscuring weakly osmiophilic transmembrane proteins. Moreover, $\mathrm{OsO}_{4}$ postfixation can lead to loss and denaturation of protein from tissue (Amsterdam and Schramm, 1966; McMillan and Luftig, 1973). For analysis of protein-rich compartments like the postsynaptic density (PSD), techniques that better preserve protein may provide a useful new perspective. We employ here an osmium-free protocol that provides excellent preservation and yields high-resolution images, while emphasizing proteins over lipids, yielding a new "proteocentric" view of synaptic structure.

\section{MATERIALS AND METHODS}

\section{Tissue preparation}

All animal procedures were strictly in accord with NIH and IACUC rules. Eight adult male Sprague-Dawley rats (2-4 months old, 250-500 g, from Charles River) were deeply anesthetized with pentobarbital $(60 \mathrm{mg} / \mathrm{kg}$, i.p.) and sacrificed by intra-aortic perfusion with mixed aldehydes (2\% glutaraldehyde and $2 \%$ freshly depolymerized paraformaldehyde) in $0.1 \mathrm{M}$ phosphate buffer (PB; $\mathrm{pH} 7.4$ ), after a brief flush with heparinized saline; the interval between opening the chest and flow of fixative into the aorta was kept to no more than 60 seconds.

All illustrations except Figure 1A are from R2869, a 350-g rat perfused for 1 hour with mixed aldehydes; this material was selected for particularly favorable surgical technique and histological excellence. Figure 1A (which illustrates material postfixed with osmium tetroxide) is from R3825, a 360-g rat fixed in the same manner, selected to provide comparable material.

Blocks of fixed forebrain were sectioned on a Vibratome at 50- $\mu \mathrm{m}$ thickness and stored in $\mathrm{PB}$ at $4^{\circ} \mathrm{C}$. Sections containing regions of interest were prepared for electron microscopy according to the approach described in Phend et al. (1995), incubating floating sections in 
tannic acid and uranyl acetate prior to dehydration. Additional metal salts were tested as adjuvants in preliminary experiments, including potassium ferrocyanide, chromium potassium sulfate, osmium trichloride, iridium tetrabromide, and mercuric acetate. The combination of uranyl acetate with $0.1 \% \mathrm{PtCl}_{4}$ provided especially fine grain and excellent visualization of structure. For that reason, the present manuscript is based primarily on observations from material prepared with uranyl acetate and $\mathrm{PtCl}_{4}$.

Sections collected in glass vials were incubated on a shaker at $4^{\circ} \mathrm{C}$ for 40 minutes in $1 \%$ tannic acid (Mallinkrodt, Paris, NY) in 0.1 M maleate buffer, pH 6.0 (MB), then for 20 minutes in $0.1 \% \mathrm{CaCl}_{2}$ in $\mathrm{MB}$, and then for 40 minutes in a mixture of $1 \%$ uranyl acetate (Electron Microscopy Sciences, Ft. Washington, PA) and $0.1 \% \mathrm{PtCl}_{4}$ (Pfaltz \& Bauer, Waterbury, CT). Sections were then rinsed and dehydrated through ethanol into propylene oxide; when the concentration of ethanol exceeded 50\%, the temperature was lowered by incubation over salted ice at $-15^{\circ} \mathrm{C}$. After dehydration, sections were infiltrated with EponSpurr resin, sandwiched between sheets of Aclar plastic, and heat-polymerized at $60^{\circ} \mathrm{C}$. Chips of S1 cortex and CA1 hippocampus were glued to plastic blocks, and thin sections were cut on an ultramicrotome with a diamond knife. For routine histology, $\sim 50-\mathrm{nm}$ sections were collected on 400-mesh copper grids; for electron tomography, thicker $(\sim 120 \mathrm{~nm})$ sections were collected on 100-mesh hexagonal gold grids. Grids were poststained with uranyl acetate and Sato's lead (Hanaichi et al., 1986).

\section{Electron tomography}

Ten-nanometer colloidal gold particles were deposited on the section to serve as fiducial marks; grids were then coated with a thin $(\sim 10 \mathrm{~nm})$ layer of carbon to improve stability under the electron beam. A total of 21 tomograms from layer $2 / 3$ of the SI cortex and the stratum radiatum of the CA1 hippocampus were analyzed, including 10 generated from single-tilt series ( 6 from CA1 and 4 from SI cortex) and 11 from double-tilt series ( 3 from $\mathrm{CA} 1$ and 8 from SI). We focused attention on synapses onto large (>400-nm-diameter), mushroom-shaped spines (as defined by Peters and Kaiserman-Abramof, 1970).

Single-tilt series were collected by using an FEI (Hillsboro, OR) Tecnai $\mathrm{G}^{2}$ Twin electron microscope operated at $200 \mathrm{kV}$. Images were recorded with a 2,048 $\times 2,048 \mathrm{CCD}$ camera. The FEI tomography acquisition software package was used to acquire tilt series (from $-65^{\circ}$ to $+65^{\circ}$, with $2^{\circ}$ increments). However, in view of the superior quality provided by doubletilt series, we do not illustrate any of the single-tilt data.

Double-tilt series were collected with a JEOL 4000EX electron microscope operated at 400 $\mathrm{kV}$. The specimens were irradiated before a tilt series was initiated, to limit anisotropic specimen thinning during image collection. A computer-controlled goniometer was used to tilt the stage in $2^{\circ}$ increments from $-70^{\circ}$ to $+70^{\circ}$ about an axis perpendicular to the optical axis of the microscope, using in-house software; after acquisition of a complete tilt series, the goniometer was rotated $90^{\circ}$ for acquisition of a second tilt series. For high-resolution tomograms, tilt series were recorded by using either a slow-scan CCD camera or film at $15,000-20,000 \times$ magnification; to provide an overview of synaptic organization, three tomograms were collected at lower magnifications $(3,000-5,000 \times)$. The CCD camera was $1,960 \times 2,560$ pixels, with single-pixel resolution of $1.1 \mathrm{~nm}$. For film tilt series, negatives were digitized by using scanners with pixel resolutions ranging from 0.7 to $2.2 \mathrm{~nm}$. Illumination was held to near parallel beam conditions, and optical density was maintained constant by varying the exposure time.

In initial work, the IMOD software package (http://bio3-d.colorado.edu/imod; Kremer et al., 1996) was used for the entire procedure of image alignment and reconstruction. In subsequent work, IMOD was used for rough alignment, and the fine alignment and 
reconstruction were performed with the TxBR software package (Lawrence et al., 2006). Tomographic reconstructions presented in this paper were deposited in the Cell Centered Database (http://ccdb.ucsd.edu), where they are available under project P1194 (http:// ccdb.ucsd.edu/sand/main?

stype=lite \&keyword=P1194\&event=display \&Submit=Go\&start=1).

We used Corel Draw v.14 (Corel, Ontario, Canada) to adjust brightness and contrast, and compose final plates. These adjustments were done exclusively to enhance the presentation quality of figures, without altering the scientific data content of the images.

\section{Atomic docking procedure}

To reduce noise, tomographic slices were processed with a non-local means algorithm, reducing the noise while still preserving fine detail. The pixel values are determined as a weighted average of all other pixels, where the weights are determined by the similarity of local neighborhoods (Buades et al., 2005). To reduce computation time, weighted averages were performed only over a local search area with the estimated pixel contained in the center. The size of the local neighborhood for determining the weights was set to $9 \times 9$ pixels, and the size of the search area was set to $65 \times 65$ pixels.

Regions of interest were selected manually for atomic docking analysis. A 3D watershed transform (Volkmann, 2002) was used to analyze the subunit composition of the extracted density. Searches for helical symmetry parameters were performed by optimizing the correlation between tentative helical subunits within the extracted density, subject to variations of the helical rise, helical angle, and position of the helical axis. An atomic filament model was created by using a high-resolution EM-derived model for filamentous actin monomers (Fujii et al., 2010) and applying symmetry parameters derived from the data. Correlation-based density fitting algorithms implemented in the CoAn package (http:// coan.burnham.org/; Volkmann and Hanein, 1999, 2003) were then used to fit the actinfilament model into the densities and to quantify the fitting quality. Fourier-shell correlation analysis was also performed with the CoAn package. The 0.5 frequency-space cutoff criterion was used for resolution estimation.

\section{RESULTS}

\section{Overview}

TEM examination of neuropil in superficial layers of the neocortex and stratum radiatum of the hippocampus reveals morphology typical of our processing technique, which differs from that of osmium-treated material. The material is highly contrasted. Membranes are sharply revealed in negative contrast, giving them an appearance different from that seen after processing with osmium (Fig. 1). Protein-rich compartments like the PSD and the presynaptic active zone are far more densely stained than in osmium-processed material, and cytoskeletal features within the spine are prominent.

Tomographic processing led to dramatic sharpening, reflecting the ability of electron tomography to provide virtual ultrathin $(<5 \mathrm{~nm})$ sections, thus minimizing the image degradation inherent in TEM of plastic sections. The raw images were fuzzy, reflecting the relatively thick ( 120-nm) sections used for acquisition of tilt series (Fig. 2A). In contrast, tomographic processing reveals much clearer ultrastructural detail, especially tomograms from double-tilt series: plasma membranes are sharp, intracellular particles are crisply defined, and otherwise obscure profiles can be readily identified by following them through the tomographic stack (Fig. 2B; see also Movies 1 and 2 in the Supplemental Material). The original data-set is too large to publish, but can be downloaded from the Cell Centered Data 
Base (http://ccdb.ucsd.edu, under project P1194), making it possible to visualize the raw dataset (see colorized projection in Fig. 2C and Supplementary Fig. 1).

\section{The presynaptic terminal}

The presynaptic terminal was bounded by a sharply defined electron-lucent plasma membrane coated with tiny electron-dense blobs (Fig. 2B, inset), likely corresponding to integral membrane proteins, including pumps and ion channels. Electron-dense features were seldom present within the plasma membrane itself; evidently, the uranyl/lead poststaining reagents were excluded from these lipid-rich zones.

Likewise, the appearance of presynaptic vesicles differs from osmium-treated material, in which vesicles are typically seen as hollow circles defined by two concentric electron-dense rings (Fig. 1); in our material, they are instead defined by a single dense ring. Careful examination reveals that these rings are generated by numerous discrete particles distributed along the circumference, presumably reflecting proteins that line the exterior surface of the lipid bilayer of the vesicular membrane; particles also line the interior of the bilayer, but to a far lesser degree (Fig. 2B).

In general, vesicles were linked to each other and to the plasma membrane. Despite some degree of biological variability and the lower image quality of single-tilt tomograms, we found a generally consistent pattern of tethering among presynaptic vesicles. Typically, vesicles were connected to three to six neighbors, either by direct contact (Fig. 3A, dotted circles), or bridged by short ( 10-20-nm) electron-dense filaments (Fig. 3A, blue arrow). Vesicles lying at the outer edge of the pool were attached to the plasma membrane with longer ( 20-60-nm) filaments (Fig. 3A, black arrows; Fig. 3B). A 3-dimentional rendering of the large-scale organization of vesicles in the pre-synaptic terminal is shown in Figure 3C.

\section{The postsynaptic spine}

The postsynaptic spine was typically far less packed with organelles than the presynaptic terminal (Figs. 2B, 4A). Nevertheless, the spine contained more electron-dense material than seen with $\mathrm{OsO}_{4}$ protocols (Fig. 1), presumably reflecting our sample preparation technique, which uses tannic acid to help preserve cytoskeletal integrity (LaFountain et al., 1977; Maupin and Pollard, 1983).

A network of thin filaments could be visualized throughout the spine. Short stretches of "naked" filament were interspersed with regions where blobs of electron-dense material coated the filament. Although filaments could run in a straight line for $100 \mathrm{~nm}$ or more, more commonly they were shorter, often following a crooked or tortuous path (perhaps reflecting dehydration-associated shrinkage). The filaments frequently intersected with each other, creating a complex mesh that filled the spine. In each tomogram studied, we noted scattered loci where multiple filaments joined together, associated with a marked accumulation of electron-dense material (illustrated schematically by yellow circles in Fig. $4 \mathrm{~B}, \mathrm{C})$. The filament network made numerous contacts with the plasma membrane. Typically, a small accumulation of electron-dense material was visible at these points of contact. Throughout our material, we noted an accumulation of densely branched filaments flanking the edges of the PSD (dotted ellipses, Fig. 4A,D) and lateral to it (arrows, Fig. $4 \mathrm{~A}, \mathrm{D})$.

The complexity of this filamentous network made precise reconstruction unfeasible; for example, at some points it was impossible to establish whether two filaments intersected, or instead crossed without touching (cf. Korobova and Svitkina, 2010). Nevertheless, with care we could make a reasonably accurate diagram of the large-scale structure of the 
"spinoskeleton" in double-tilt material acquired at high magnifications, either manually (Fig. 4B,C; also see interactive 3D PDF in Supplementary Fig. 2) or by using skeletonization algorithms (Fig 4E; also see Supplementary Fig. 3 and Movie 3). Several features that are difficult to recognize in a tomographic stack are more easily appreciated in these diagrams. For example, one sees an increased density of filament branch-points $\sim 20-30 \mathrm{~nm}$ from the plasma membrane (red dots in Fig. 4B,C), especially at the lateral edge of the PSD (dotted circles, Fig. 4C).

Segmentation allowed us to determine the distribution of filament thickness and length (Fig. $4 \mathrm{~F}, \mathrm{G})$ : the median diameter of filaments $(\mathrm{n}=4,676)$ was $8.6 \mathrm{~nm}$ (excluding 512 filaments shorter than $20 \mathrm{~nm}$ ), whereas median filament length was $49.3 \mathrm{~nm}$ (excluding 585 filaments thinner than $4 \mathrm{~nm}$ or thicker than $20 \mathrm{~nm}$ ). These values imply an overall filament density within the spine of $\sim 12,000 \mu \mathrm{m}$ of filament per $\mu \mathrm{m}^{3}$ of spine.

The observed filament thickness is consistent with the diameter of F-actin. To further investigate the issue, we compared filamentous structures from a tomogram (Fig. 5A) with an atomic model for F-actin, derived from high-resolution cryo-electron microscopy (Fujii et al., 2010). The extracted density proved to be an excellent fit to the model (Fig. 5B,C). After symmetrization, the filaments in the tomograms indeed represented actin filaments faithfully, down to a resolution of $4 \mathrm{~nm}$.

\section{The presynaptic active zone}

The tomographic slices provide clear visualization of a series of large electron-dense blobs arrayed along the presynaptic apposition (Fig. 6A, Movie 4). These blobs, corresponding to the "dense projections" reported in the older literature, were more prominent in our material than after osmium fixation. Examination of tomograms from low-magnification tilt series (3 $\times 3$ microm; data not show) revealed that dense projections could be organized into a geometric lattice reminiscent of the classical description by Pfenninger et al. (1972), but this pattern was not consistent; in other synapses the dense projections instead seemed randomly distributed along the pre-synaptic membrane.

Notwithstanding considerable variability in their internal structure, the dense projections shared common features: a wide base typically lay beneath a main pillar of $\sim 40-\mathrm{nm}$ thickness that extends $\sim 60 \mathrm{~nm}$ into the cytoplasm. The dense projections in our material exhibited a stubby tree-like structure, giving rise to several short branches that made direct contact with synaptic vesicles (Fig. 6B). 3D reconstruction revealed that each dense projection contacted four to six vesicles (Fig. 6C). Clathrin-coated vesicles were occasionally seen at some distance from the active zone (Fig. 3B), but we never observed clathrin-coated vesicles at the active zone itself.

Away from the active zone, presynaptic vesicles seldom approached closer than $\sim 30 \mathrm{~nm}$ to the plasma membrane, whereas at the active zone, some vesicles made direct contact with the membrane (Fig. 6D). This region of contact between docked vesicles and plasma membrane appeared to contain two lipid bilayers (Fig. 6D), with only a thin $(\sim 5-\mathrm{nm})$ layer of electron-dense material dividing the vesicle from the plasma membrane. We also saw vesicles directly fused to the membrane; in many cases these fusing vesicles were deformed and shrunken, seemingly caught in the process of exocytosis (Fig. 6E, Movie 4). In these cases, the internal surface of the lipid bilayer was strongly contrasted; we presume that tannic acid had improved access to the interior of these vesicles during the initial stages of tissue processing. The abundance of these fusion events exceeds what one would expect in vivo (Heuser et al., 1979); the onset of chemical fixation presumably triggered massive exocytosis. Importantly, all docked and fusing vesicles studied were in close contact with a dense projection. 


\section{The synaptic cleft}

A somewhat variable $20-30$-nm spacing between the two plasma membranes was seen at the synaptic cleft, substantially greater than at nonsynaptic regions of apposition. The synaptic cleft was packed with electron-dense material, making it difficult to analyze, although certain features were recognizable, including bridges that spanned the full extent of the cleft (Fig. 7A-C), intermingled with the dense feltwork of cleft material. Densitometry revealed a markedly increased electron density adjacent to the edges of the plasma membrane, with modest evidence of increased density in the central zone (marked by vertical black rectangle in Fig. 7D), consistent with results from electron tomography of cryo-fixed synaptosomes (Lucic et al., 2005b). At the edges of the synapse, the cleft space constricted, and the pre- and post-synaptic membranes often seemed to make direct contact (Fig. 7E, black lines; see also Figs. 2B, 4A), although a few nanometers may have remained between the two membranes. These physical obstacles are likely to limit diffusion within the cleft.

\section{The postsynaptic density}

The PSD as visualized by electron tomography was very jagged (Fig. 8A, Movie 4), reminiscent of high-resolution images of the biochemically isolated PSD fraction (Petersen et al., 2003). The overall appearance of the PSD, although consistent with the electron tomographic images shown in Rostaing et al. (2006), was thicker and more complex than in cultured neurons (Chen et al., 2008a). Standard TEM methods have shown that the PSD contains a dense lamina facing the synaptic cleft, and a more attenuated cytoplasmic lamina (Welch et al., 2007). Electron tomography clarified the nature of this organization: a relatively thin ( 10-20-nm) sheet of electron-dense material lay adjacent to the plasma membrane. At its lateral margin, this PSD sheet became more attenuated, ending at or just before the cleft began to pinch together (cf. Fig. 7E). Interior to this sheet, an irregular spiky network of material entered the cytoplasm of the spine. Filaments (likely to represent Factin) made contact with these cytoplasmic PSD projections. At these zones of contact, the thickness of the PSD increased, forming a pyramidal structure whose vertex contacted the filament (Fig. 8A). Densitometric analysis confirmed our visual impression of PSD structure; variations in density tangentially along the length of the synapse were of higher spatial frequency and smaller amplitude along laminar zones sampled within $10 \mathrm{~nm}$ from the plasma membrane, than along zones sampled from deeper in the cytoplasm (Fig. 8B).

\section{DISCUSSION}

Transmission electron microscopy remains the primary tool for study of synaptic morphology. The most important recent advance in instrumentation for biological electron microscopy has been the introduction of electron tomography. Here we have used electron tomography of aldehyde-fixed brain sections stabilized with tannic acid, providing a new view of the fine structure of the excitatory synapse.

\section{Methodological issues}

Specimen preparation requires fixation to stabilize the constituent molecules, thus preventing postmortem changes, but the fixation process itself can induce structural artifacts. An attractive solution is physical fixation with rapid cooling under high pressure; freezing samples into vitreous ice immobilizes the cytoplasm and inactivates enzymatic activity, while minimizing damage from ice crystals (Medalia et al., 2002; Lucic et al., 2005a; Bouchet-Marquis and Hoenger, 2011; Yahav et al., 2011). However, it is unfeasible to use this approach on vertebrate brain without preliminary surgical and hypoxic insult; for this reason, electron tomography of cryo-fixed synapses has been limited to reduced systems. Beyond the problem of cryo-fixing brain per se, cutting thin sections from native cryo-fixed 
material is challenging, and immunoprocessing requires that the sections be thawed, destroying many of the advantages of cryopreservation. Moreover, cryosections (which lack heavy metal staining) are inherently low-contrast, and exhibit poor stability under the electron beam.

The alternative is chemical fixation. To study the mammalian brain, fixation normally relies on vascular perfusion with mixed aldehydes. Chemical fixation stabilizes the cytoplasm via protein crosslinking and inactivation of proteolytic enzymes, but may lead to artifacts arising both from the relatively slow fixation process and from the crosslinking itself. Nevertheless, the use of aldehyde fixation in specimen preparation leads to surprisingly little disruption of biological structure (Reger and Escaig, 1988; Sosinsky et al., 2008). For the reasons listed above, most work on synaptic ultrastructure has relied on plastic embedding of the chemically fixed material. One strategy is to perform high-pressure freezing followed by freeze-substitution; this minimizes dehydration-associated artifacts, especially loss of lipid. However, the approach generally relies on UV polymerization of the plastic resin, implying that heavy metals (which can act to stabilize structure and enhance contrast) must be avoided or kept to a minimum.

For these reasons, most tomographic studies on the synapse (Harlow et al., 2001; Zampighi et al., 2006, 2008; Siksou et al., 2007; Nagwaney et al., 2009; Arthur et al., 2010; Perkins et al., 2010) have used chemically fixed material and $\mathrm{OsO}_{4}$, which helps to stabilize lipids while enhancing electron contrast. However, $\mathrm{OsO}_{4}$ is a strong oxidizer, and it damages the secondary structure of proteins (Lenard and Singer, 1968). Likewise, $\mathrm{OsO}_{4}$ can disrupt the integrity of protein complexes, including F-actin filaments (LaFountain et al., 1977; Maupin and Pollard, 1983). We speculate that these effects explain osmium's well-known adverse effects on tissue antigenicity.

Tannic acid was introduced to electron microscopy as a mordant to enhance electron contrast (Simionescu and Simionescu, 1976). Consistent with its long-recognized efficacy as a tissue preservative, tannic acid has been shown to stabilize supramolecular assemblies, and in particular to maintain the integrity of F-actin (Maupin and Pollard, 1983; Takagi et al., 1983). Moreover, tannic acid-based fixation preserves antigenicity for a variety of proteins (Berryman et al., 1992; Phend et al., 1995). Taken together, these traits suggest that important features of fine structure in vivo are preserved in our material, notwithstanding the disruption inherent in chemical fixation, dehydration, and plastic embedment.

Considerable evidence from model systems in the older literature suggests that the identity of the buffer used during fixation influences specimen preservation and retention of protein. We relied on phosphate, a simple and nontoxic inorganic buffer. However, phosphate is likely to reduce the effective concentration of extracellular $\mathrm{Ca}^{2+}$, considering the rather low solubility product for calcium phosphate. Because $\mathrm{Ca}^{2+}$ helps to stabilize membranes, the phosphate may have impaired membrane preservation; future work using Good buffers could address this issue (Good et al., 1966). More generally, the reader must recognize that the images shown here include a variety of artifacts not present in the native state, and that current limits on our knowledge make it difficult to know which features may be artifactual (see discussion in Griffiths, 1993).

\section{The presynaptic terminal}

Our data confirm observations from freeze-etched material and from previous electron tomographic studies showing that synaptic vesicles are linked together by a network of filaments (Fernandez-Busnadiego et al., 2010; Siksou et al., 2011). Although the overall appearance of the presynaptic terminal is generally consistent with previous reports, its fine structure differs; these differences were especially noticeable in synaptic vesicles. In our 
material, vesicles were defined by numerous electron-dense blobs organized into hollow spheres. This pattern, although not typically reported in osmium-treated material, fits biochemical evidence for an exceptionally high concentration of proteins embedded in the vesicular membrane (Takamori et al., 2006), and is consistent with the images of platinumshadowed replicas and native cryosamples shown in that paper. We believe that these blobs correspond to individual proteins or protein assemblies. Systematic study using our approach might permit implementation of "visual proteomics," allowing identification of proteins based on morphology alone (Nickell et al., 2006); supporting this possibility is our success with atomic docking of actin filaments.

As in classical (Couteaux, 1961; Gray, 1963; Bloom and Aghajanian, 1968; Pfenninger et al., 1972) and recent (Zampighi et al., 2008) studies of chemically fixed tissue, the landscape of the active zone in our material was dominated by presynaptic dense projections. The prominence of these dense projections has varied considerably in different studies; early studies of cryofixed material failed to detect them (Landis et al., 1988), raising the possibility that these structures are artifacts arising from chemical fixation. Although not reporting dense projections per se, a recent cryo-EM tomographic study showed filamentous structures linking vesicles to the active zone (Fernandez-Busnadiego et al., 2010; see also Lenzi et al., 1999; Rostaing et al., 2006; Siksou et al., 2007). We speculate that the dense projections seen in our material represent the same biological structure, after fixativeinduced chemical crosslinking and post-staining. It seems unlikely that fixation would create dense projections de novo from a homogeneous presynaptic matrix. The presence of this modular pre-synaptic structure, together with the strong association of these dense projections with docked and fusing vesicles reported here suggests that the active zone contains multiple exocytic "hot spots," perhaps associated with presynaptic calcium nanodomains (Muller et al., 2010). Interestingly, a recent study in insects shows a similar presynaptic density associated with docked vesicles (Leitinger et al., 2011).

\section{The postsynaptic spine}

It was already recognized by Fifkova and Van Harreveld (1977) that the spine cytoskeleton is dominated by F-actin. A variety of human neurocognitive disorders have been linked to abnormalities of spine morphology associated with dysregulation of the actin cytoskeleton (Newey et al., 2005; van Spronsen and Hoogenraad, 2010; Penzes and Vanleeuwen, 2011). The structural complexity of the actin network presents a formidable technical challenge, as emphasized by a recent high-resolution study using metal shadowing of spines in cultured neurons (Korobova and Svitkina, 2010). Here, electron tomography allowed us to examine the $3 \mathrm{D}$ organization of actin networks whose integrity had been preserved with tannic acid. Despite our direct evidence that the fine structure of the F-actin polymer has been preserved, the present results must be treated with caution: Our reconstructions of the cytoskeleton have been modified by artifacts introduced by dehydration and shrinkage (presumably accounting for the wavy/tortuous filaments); by the crosslinking of chemical fixation (perhaps accounting for many of the electron-dense blobs directly attached to the filaments); and by the uncertain degree of remodeling that occurred during initial stages of the fixation process. Notwithstanding these caveats, the reconstructions revealed intriguing cytoskeletal features, including the organization of contacts with the plasma membrane, and specializations at loci of filament convergence.

Extensive published evidence documenting a link between synaptic strength and actin remodeling suggests that, beyond defining the architecture of the spine, actin must play a direct role in postsynaptic function (Carlisle and Kennedy, 2005; Alvarez and Sabatini, 2007; Cingolani and Goda, 2008; Kasai et al., 2010; Svitkina et al., 2010). In this context, it is noteworthy that a dense nexus of actin filaments just lateral to the PSD was a consistent feature of all the spines examined. It is tempting to relate our structural data to accumulating 
evidence that a zone just lateral to the PSD is specialized for receptor trafficking (Newpher and Ehlers, 2009); we suggest that the perisynaptic accumulation of actin filaments reported here may be a component of this endo/exocytic zone.

Numerous contacts were seen between F-actin filaments and the PSD. Typically, the PSD was thickened, extending into the cytoplasm at these points of contact. Our results are reminiscent of the "PSD projections" previously found in electron tomograms from unfixed material after high-pressure freezing (Rostaing et al., 2006), although the overall architecture of filaments appears extended along the axodendritic axis in that material. Rostaing et al. (2006) also provided immunogold identification of at least some of their filamentous structures as F-actin, consistent with previous work (Gulley and Reese, 1981). The biochemical identity of these points of contact between filaments and the PSD remains uncertain, although biochemistry has identified a variety of actin-binding proteins within the PSD (Bockers et al., 2001; Hering and Sheng, 2003; Qualmann et al., 2004), and immunogold confirms the presence of several of these proteins on the cytoplasmic side of the PSD, including cortactin (Rostaing et al., 2006) and a-actinin, which can interact directly with the $N$-methyl-D-aspartate receptor (Wyszynski et al., 1997).

\section{CONCLUSIONS}

Electron tomography offers a powerful new tool for the analysis of synaptic structure, but specimen preparation remains problematic. Our tomographic analysis of synapses from chemically fixed brain processed according to an osmium-free protocol provides a new view. These data may help to elucidate important aspects of synaptic organization.

\section{Supplementary Material}

Refer to Web version on PubMed Central for supplementary material.

\section{Acknowledgments}

Grant sponsor: National Institutes of Health; Grant numbers: R01 NS039444 and NS35527 (to R.J.W.), P01 GM066311, P01 GM066311 (to N.V.), P41 RR004050 (to M.H.E.), and R01 GM82949 (which provides support for the Cell Centered Database; Grant sponsor: the Branfman Family Foundation (to M.H.E.).

We thank Kristen Phend for histological assistance; Ying Jones for pilot work on electron tomography; and Tom Blanpied, Michael Ehlers, Viktor Kharazia, Sridhar Raghavachari, Vladan Lučić, and Bence Rácz for comments on the manuscript.

\section{LITERATURE CITED}

Alvarez VA, Sabatini BL. Anatomical and physiological plasticity of dendritic spines. Annu Rev Neurosci. 2007; 30:79-97. [PubMed: 17280523]

Amsterdam A, Schramm M. Rapid release of the zymogen granule protein by osmium tetroxide and its retention during fixation by glutaraldehyde. J Cell Biol. 1966; 29:199-207. [PubMed: 5335826]

Arthur CP, Dean C, Pagratis M, Chapman ER, Stowell MH. Loss of synaptotagmin IV results in a reduction in synaptic vesicles and a distortion of the Golgi structure in cultured hippocampal neurons. Neuroscience. 2010; 167:135-142. [PubMed: 20138128]

Berryman MA, Porter WR, Rodewald RD, Hubbard AL. Effects of tannic acid on antigenicity and membrane contrast in ultrastructural immunocytochemistry. J Histochem Cytochem. 1992; 40:845857. [PubMed: 1350287]

Bloom FE, Aghajanian GK. Fine structural and cyto-chemical analysis of the staining of synaptic junctions with phosphotungstic acid. J Ultrastruct Res. 1968; 22:361-375. [PubMed: 4173151]

Bockers TM, Mameza MG, Kreutz MR, Bockmann J, Weise C, Buck F, Richter D, Gundelfinger ED, Kreienkamp HJ. Synaptic scaffolding proteins in rat brain. Ankyrin repeats of the multidomain 
Shank protein family interact with the cytoskeletal protein alpha-fodrin. J Biol Chem. 2001; 276:40104-40112. [PubMed: 11509555]

Bouchet-Marquis C, Hoenger A. Cryo-electron tomography on vitrified sections: a critical analysis of benefits and limitations for structural cell biology. Micron. 2011; 42:152-162. [PubMed: 20675145]

Buades A, Coll B, Morel JM. A non-local algorithm for image denoising. IEEE Proc Comp Vis Patt Rec. 2005:60-65.

Carlisle HJ, Kennedy MB. Spine architecture and synaptic plasticity. Trends Neurosci. 2005; 28:182187. [PubMed: 15808352]

Chen X, Winters C, Azzam R, Li X, Galbraith JA, Leapman RD, Reese TS. Organization of the core structure of the postsynaptic density. Proc Natl Acad Sci U S A. 2008a; 105:4453-4458. [PubMed: 18326622]

Chen X, Winters CA, Reese TS. Life inside a thin section: tomography. J Neurosci. 2008b; 28:93219327. [PubMed: 18799665]

Cingolani LA, Goda Y. Actin in action: the interplay between the actin cytoskeleton and synaptic efficacy. Nat Rev Neurosci. 2008; 9:344-356. [PubMed: 18425089]

Collins MO, Grant SG. Supramolecular signalling complexes in the nervous system. Subcell Biochem. 2007; 43:185-207. [PubMed: 17953395]

Couteaux R. Principaux critères morphologiques et cytochimiques utilisables aujourd'hui pour dfinir les divers types de synapses. Actual Neurophysiol. 1961; 3:145-173.

Fernandez-Busnadiego R, Zuber B, Maurer UE, Cyrklaff M, Baumeister W, Lucic V. Quantitative analysis of the native presynaptic cytomatrix by cryoelectron tomography. J Cell Biol. 2010; 188:145-156. [PubMed: 20065095]

Fifkova E, Van Harreveld A. Long-lasting morphological changes in dendritic spines of dentate granular cells following stimulation of the entorhinal area. J Neurocytol. 1977; 6:211-230. [PubMed: 856951]

Frey TG, Perkins GA, Ellisman MH. Electron tomography of membrane-bound cellular organelles. Annu Rev Biophys Biomol Struct. 2006; 35:199-224. [PubMed: 16689634]

Fujii T, Iwane AH, Yanagida T, Namba K. Direct visualization of secondary structures of F-actin by electron cryo-microscopy. Nature. 2010; 467:724-728. [PubMed: 20844487]

Good NE, Winget GD, Winter W, Connolly TN, Izawa S, Singh RM. Hydrogen ion buffers for biological research. Biochemistry. 1966; 5:467-477. [PubMed: 5942950]

Gray EG. Electron microscopy of presynaptic organelles of the spinal cord. J Anat. 1963; 97:101-106. [PubMed: 13949972]

Griffiths, G. Fine structure immunocytochemistry. Berlin: Springer Verlag; 1993.

Gulley RL, Reese TS. Cytoskeletal organization at the postsynaptic complex. J Cell Biol. 1981; 91:298-302. [PubMed: 7197681]

Hanaichi T, Sato T, Iwamoto T, Malavasi-Yamashiro J, Hoshino M, Mizuno N. A stable lead by modification of Sato's method. J Electron Microsc (Tokyo). 1986; 35:304-306. [PubMed: 2440973]

Harlow ML, Ress D, Stoschek A, Marshall RM, McMahan UJ. The architecture of active zone material at the frog's neuromuscular junction. Nature. 2001; 409:479-484. [PubMed: 11206537]

Hering H, Sheng M. Activity-dependent redistribution and essential role of cortactin in dendritic spine morphogenesis. J Neurosci. 2003; 23:11759-11769. [PubMed: 14684878]

Heuser JE, Reese TS, Dennis MJ, Jan Y, Jan L, Evans L. Synaptic vesicle exocytosis captured by quick freezing and correlated with quantal transmitter release. J Cell Biol. 1979; 81:275-300. [PubMed: 38256]

Hurbain I, Sachse M. The future is cold: cryo-preparation methods for transmission electron microscopy of cells. Biol Cell. 2011; 103:405-20. [PubMed: 21812762]

Kasai H, Fukuda M, Watanabe S, Hayashi-Takagi A, Noguchi J. Structural dynamics of dendritic spines in memory and cognition. Trends Neurosci. 2010; 33:121-129. [PubMed: 20138375]

Korobova F, Svitkina T. Molecular architecture of synaptic actin cytoskeleton in hippocampal neurons reveals a mechanism of dendritic spine morphogenesis. Mol Biol Cell. 2010; 21:165-176. [PubMed: 19889835] 
Kremer JR, Mastronarde DN, McIntosh JR. Computer visualization of three-dimensional image data using IMOD. J Struct Biol. 1996; 116:71-76. [PubMed: 8742726]

LaFountain JR Jr, Zobel CR, Thomas HR, Galbreath C. Fixation and staining of F-actin and microfilaments using tannic acid. J Ultrastruct Res. 1977; 58:78-86. [PubMed: 64620]

Landis DM, Hall AK, Weinstein LA, Reese TS. The organization of cytoplasm at the presynaptic active zone of a central nervous system synapse. Neuron. 1988; 1:201-209. [PubMed: 3152289]

Lawrence A, Bouwer JC, Perkins G, Ellisman MH. Transform-based backprojection for volume reconstruction of large format electron microscope tilt series. J Struct Biol. 2006; 154:144-167. [PubMed: 16542854]

Leis A, Rockel B, Andrees L, Baumeister W. Visualizing cells at the nanoscale. Trends Biochem Sci. 2009; 34:60-70. [PubMed: 19101147]

Leitinger G, Masich S, Neumuller J, Pabst MA, Pavelka M, Rind FC, Shupliakov O, Simmons PJ, Kolb D. Structural organization of the presynaptic density at identified synapses in the locust central nervous system. J Comp Neurol. 2011; 520:384-400. [PubMed: 21826661]

Lenard J, Singer SJ. Alteration of the conformation of proteins in red blood cell membranes and in solution by fixatives used in electron microscopy. J Cell Biol. 1968; 37:117-121. [PubMed: 5645836]

Lenzi D, Runyeon JW, Crum J, Ellisman MH, Roberts WM. Synaptic vesicle populations in saccular hair cells reconstructed by electron tomography. J Neurosci. 1999; 19:119-132. [PubMed: 9870944]

Lucic V, Forster F, Baumeister W. Structural studies by electron tomography: from cells to molecules. Annu Rev Biochem. 2005a; 74:833-865. [PubMed: 15952904]

Lucic V, Yang T, Schweikert G, Forster F, Baumeister W. Morphological characterization of molecular complexes present in the synaptic cleft. Structure. 2005b; 13:423-434. [PubMed: 15766544]

Maupin P, Pollard TD. Improved preservation and staining of HeLa cell actin filaments, clathrincoated membranes, and other cytoplasmic structures by tannic acid-glutaraldehyde-saponin fixation. J Cell Biol. 1983; 96:51-62. [PubMed: 6186673]

McMillan PN, Luftig RB. Preservation of erythrocyte ghost ultrastructure achieved by various fixatives. Proc Natl Acad Sci U S A. 1973; 70:3060-3064. [PubMed: 4131743]

Medalia O, Weber I, Frangakis AS, Nicastro D, Gerisch G, Baumeister W. Macromolecular architecture in eukaryotic cells visualized by cryoelectron tomography. Science. 2002; 298:12091213. [PubMed: 12424373]

Muller CS, Haupt A, Bildl W, Schindler J, Knaus HG, Meissner M, Rammner B, Striessnig J, Flockerzi V, Fakler B, Schulte U. Quantitative proteomics of the Cav2 channel nano-environments in the mammalian brain. Proc Natl Acad Sci U S A. 2010; 107:14950-14957. [PubMed: 20668236]

Nagwaney S, Harlow ML, Jung JH, Szule JA, Ress D, Xu J, Marshall RM, McMahan UJ. Macromolecular connections of active zone material to docked synaptic vesicles and presynaptic membrane at neuromuscular junctions of mouse. J Comp Neurol. 2009; 513:457-468. [PubMed: 19226520]

Newey SE, Velamoor V, Govek EE, Van Aelst L. Rho GTPases, dendritic structure, and mental retardation. J Neurobiol. 2005; 64:58-74. [PubMed: 15884002]

Newpher TM, Ehlers MD. Spine microdomains for post-synaptic signaling and plasticity. Trends Cell Biol. 2009; 19:218-227. [PubMed: 19328694]

Nickell S, Kofler C, Leis AP, Baumeister W. A visual approach to proteomics. Nat Rev Mol Cell Biol. 2006; 7:225-230. [PubMed: 16482091]

Penzes P, Vanleeuwen JE. Impaired regulation of synaptic actin cytoskeleton in Alzheimer's disease. Brain Res Rev. 2011; 67:184-192. [PubMed: 21276817]

Perkins GA, Tjong J, Brown JM, Poquiz PH, Scott RT, Kolson DR, Ellisman MH, Spirou GA. The micro-architecture of mitochondria at active zones: electron tomography reveals novel anchoring scaffolds and cristae structured for high-rate metabolism. J Neurosci. 2010; 30:1015-1026. [PubMed: 20089910] 
Peters A, Kaiserman-Abramof IR. The small pyramidal neuron of the rat cerebral cortex. The perikaryon, dendrites and spines. Am J Anat. 1970; 127:321-55. [PubMed: 4985058]

Petersen JD, Chen X, Vinade L, Dosemeci A, Lisman JE, Reese TS. Distribution of postsynaptic density (PSD)-95 and Ca2+/calmodulin-dependent protein kinase II at the PSD. J Neurosci. 2003; 23:11270-11278. [PubMed: 14657186]

Pfenninger K, Akert K, Moor H, Sandri C. The fine structure of freeze-fractured presynaptic membranes. J Neurocytol. 1972; 1:129-149. [PubMed: 4358835]

Phend KD, Rustioni A, Weinberg RJ. An osmium-free method of Epon embedment that preserves both ultra-structure and antigenicity for post-embedding immunocytochemistry. J Histochem Cytochem. 1995; 43:283-292. [PubMed: 7532656]

Qualmann B, Boeckers TM, Jeromin M, Gundelfinger ED, Kessels MM. Linkage of the actin cytoskeleton to the postsynaptic density via direct interactions of Abp1 with the ProSAP/Shank family. J Neurosci. 2004; 24:2481-2495. [PubMed: 15014124]

Reger JF, Escaig F. A comparative fine structure study of rat cerebral cortex following ultra-rapid freezing and conventional chemical fixation procedures. J Submicrosc Cytol Pathol. 1988; 20:691-700. [PubMed: 3147130]

Rostaing P, Real E, Siksou L, Lechaire JP, Boudier T, Boeckers TM, Gertler F, Gundelfinger ED, Triller A, Marty S. Analysis of synaptic ultrastructure without fixative using high-pressure freezing and tomography. Eur J Neurosci. 2006; 24:3463-3474. [PubMed: 17229095]

Siksou L, Rostaing P, Lechaire JP, Boudier T, Ohtsuka T, Fejtova A, Kao HT, Greengard P, Gundelfinger ED, Triller A, Marty S. Three-dimensional architecture of presynaptic terminal cytomatrix. J Neurosci. 2007; 27:6868-6877. [PubMed: 17596435]

Siksou L, Triller A, Marty S. Ultrastructural organization of presynaptic terminals. Curr Opin Neurobiol. 2011; 21:261-268. [PubMed: 21247753]

Simionescu N, Simionescu M. Galloylglucoses of low molecular weight as mordant in electron microscopy. I. Procedure, and evidence for mordanting effect. J Cell Biol. 1976; 70:608-621. [PubMed: 783172]

Sosinsky GE, Crum J, Jones YZ, Lanman J, Smarr B, Terada M, Martone ME, Deerinck TJ, Johnson JE, Ellisman MH. The combination of chemical fixation procedures with high pressure freezing and freeze substitution preserves highly labile tissue ultrastructure for electron tomography applications. J Struct Biol. 2008; 161:359-371. [PubMed: 17962040]

Svitkina T, Lin WH, Webb DJ, Yasuda R, Wayman GA, Van Aelst L, Soderling SH. Regulation of the postsynaptic cytoskeleton: roles in development, plasticity, and disorders. J Neurosci. 2010; 30:14937-14942. [PubMed: 21068295]

Takagi M, Parmley RT, Denys FR, Kageyama M, Yagasaki H. Ultrastructural distribution of sulfated complex carbohydrates in elastic cartilage of the young rabbit. Anat Rec. 1983; 207:547-556. [PubMed: 6670752]

Takamori S, Holt M, Stenius K, Lemke EA, Gronborg M, Riedel D, Urlaub H, Schenck S, Brugger B, Ringler P, Muller SA, Rammner B, Grater F, Hub JS, De Groot BL, Mieskes G, Moriyama Y, Klingauf J, Grubmuller H, Heuser J, Wieland F, Jahn R. Molecular anatomy of a trafficking organelle. Cell. 2006; 127:831-846. [PubMed: 17110340]

Van Harreveld A, Trubatch J, Steiner J. Rapid freezing and electron microscopy for the arrest of physiological processes. J Microsc. 1974; 100:189-98. [PubMed: 4597871]

Van Spronsen M, Hoogenraad CC. Synapse pathology in psychiatric and neurologic disease. Curr Neurol Neurosci Rep. 2010; 10:207-214. [PubMed: 20425036]

Volkmann N. A novel three-dimensional variant of the watershed transform for segmentation of electron density maps. J Struct Biol. 2002; 138:123-129. [PubMed: 12160708]

Volkmann N, Hanein D. Quantitative fitting of atomic models into observed densities derived by electron microscopy. J Struct Biol. 1999; 125:176-184. [PubMed: 10222273]

Volkmann N, Hanein D. Docking of atomic models into reconstructions from electron microscopy. Methods Enzymol. 2003; 374:204-225. [PubMed: 14696375]

Welch JM, Lu J, Rodriguiz RM, Trotta NC, Peca J, Ding JD, Feliciano C, Chen M, Adams JP, Luo J, Dudek SM, Weinberg RJ, Calakos N, Wetsel WC, Feng G. Corticostriatal synaptic defects and OCD-like behaviours in Sapap3-mutant mice. Nature. 2007; 448:894-900. [PubMed: 17713528] 
Wyszynski M, Lin J, Rao A, Nigh E, Beggs AH, Craig AM, Sheng M. Competitive binding of alphaactinin and calmodulin to the NMDA receptor. Nature. 1997; 385:439-442. [PubMed: 9009191]

Yahav T, Maimon T, Grossman E, Dahan I, Medalia O. Cryo-electron tomography: gaining insight into cellular processes by structural approaches. Curr Opin Struct Biol. 2011; 21:670-677. [PubMed: 21813274]

Zampighi GA, Zampighi LM, Fain N, Lanzavecchia S, Simon SA, Wright EM. Conical electron tomography of a chemical synapse: vesicles docked to the active zone are hemi-fused. Biophys J. 2006; 91:2910-2918. [PubMed: 16877508]

Zampighi GA, Fain N, Zampighi LM, Cantele F, Lanzavecchia S, Wright EM. Conical electron tomography of a chemical synapse: polyhedral cages dock vesicles to the active zone. J Neurosci. 2008; 28:4151-4160. [PubMed: 18417694] 

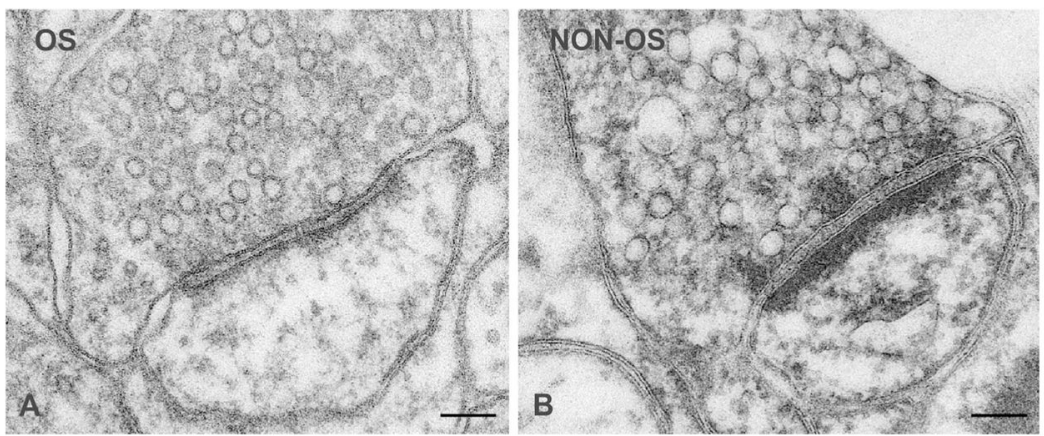

Figure 1.

TEM images illustrate the influence of two different protocols on ultrastructure. A: Axospinous synapse (stratum radiatum of CA1 hippocampus) from material postfixed with $\mathrm{OsO}_{4}$ according to standard protocol (osmicated [OS]). B: Axospinous synapse (stratum radiatum of CA1 hippocampus) from nonosmicated (NON-OS) material, prepared according to the technique used for tomography. The smooth, clearly defined membranes and internal organelles revealed with $\mathrm{OsO}_{4}$ are more aesthetic and easier to understand than the highcontrast image on the right, but many ultrastructural details are better defined with our osmium-free protocol. Scale bar $=100 \mathrm{~nm}$ in A,B. 


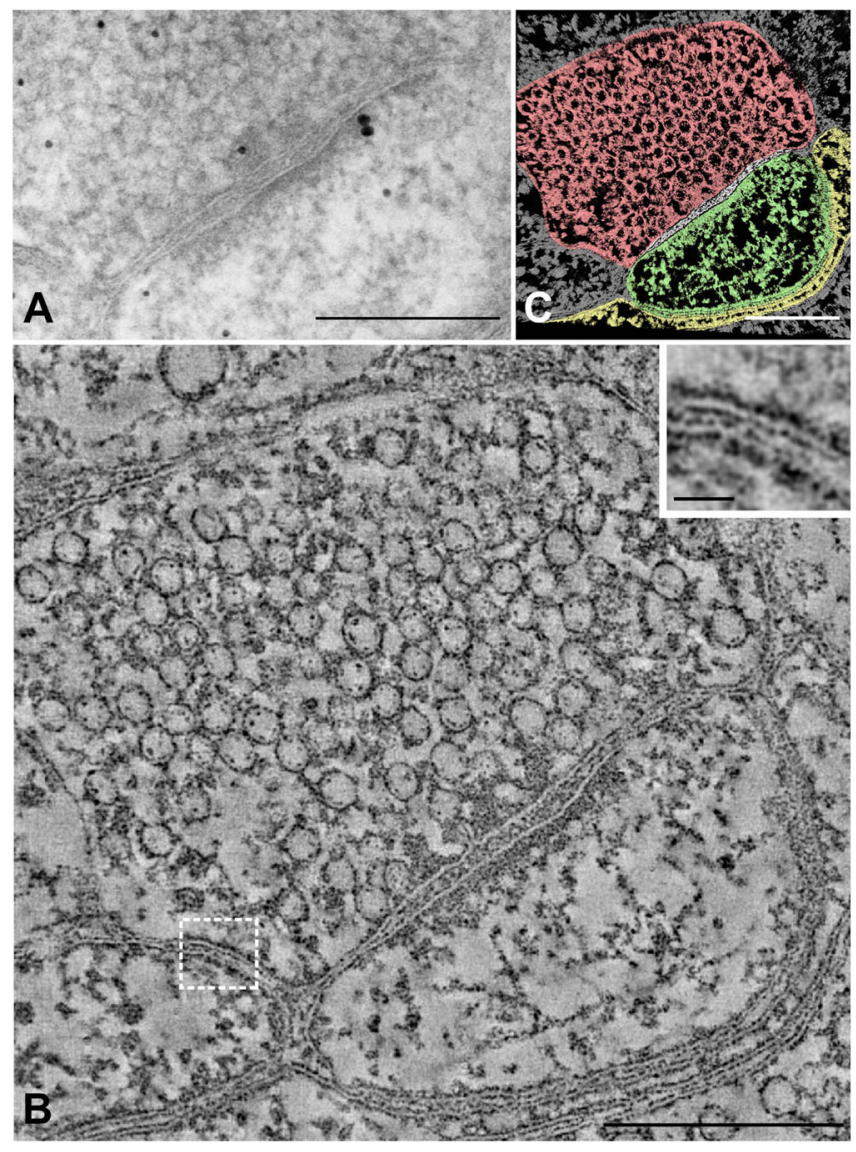

Figure 2.

Electron tomography of an axospinous synapse in cerebral cortex (layer II-III of S1 from rat R2869; see Materials and Methods). The subsequent figures are from this synapse, except as noted. A: A raw TEM image of the field used to generate the tomographic stack. The general impression of fuzziness reflects the relatively thick $(\sim 120-\mathrm{nm})$ section and high (400-KV) accelerating voltage used for image acquisition. Small black dots are 10-nm colloidal gold particles applied to the section surface, used as fiducial markers. A dual-axis tilt series of images from this synapse was collected and processed for electron tomographic reconstruction (see Materials and Methods). B: A representative ultrathin virtual tomographic section. Inset (enlargement of boxed region) shows the plasma membrane more clearly; the external surfaces of the lipid bilayer are lined with electron-dense particles. C: A projection of 11 tomographic slices using ImageJ (W.S. Rasband, ImageJ, National Institutes of Health, Bethesda, MD, http://rsb.info.nih.gov/ij/1997-2011). Red, presynaptic terminal; green, postsynaptic spine; yellow, astrocytic process. Scale bar $=250 \mathrm{~nm}$ in A-C; $25 \mathrm{~nm}$ in inset in B. 


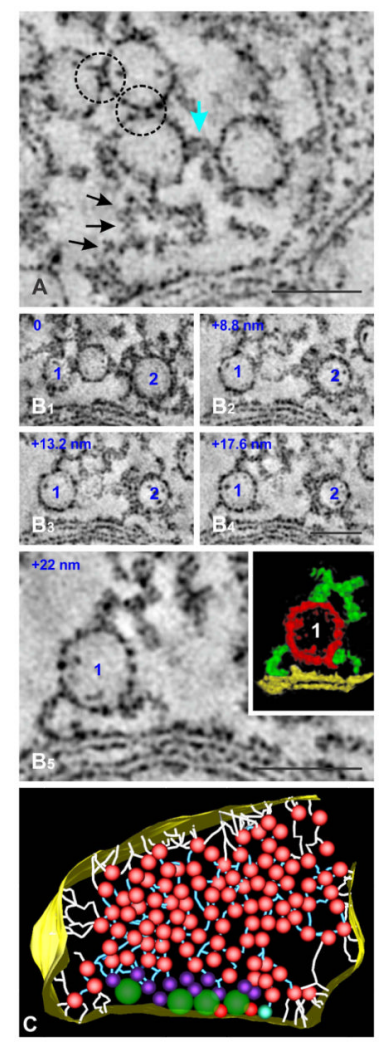

Figure 3.

Presynaptic vesicles. A: Connections made by synaptic vesicles. Two examples of direct membrane appositions between vesicles are circled; these appositions are commonly seen within vesicle clusters. Blue arrow points to a short filament connecting two adjacent vesicles; black arrows point to a longer filament that connects a vesicle to the nonsynaptic plasma membrane. $\mathbf{B}_{\mathbf{1}}-\mathbf{B}_{\mathbf{5}}$ : A Z-series showing several presynaptic vesicles; one of these (\#2) exhibits a clathrin coat. Note that each section contains distinct fine detail, documenting the excellent $\mathrm{z}$-axis resolution of the tomogram. The $3 \mathrm{D}$ projection in inset $\left(\mathrm{B}_{5}\right)$ includes seven sections through the center of vesicle \#1. C: A manual reconstruction of an 88-nmthick slice through the terminal, generated with IMOD software (Kremer et al., 1996), from a stack of forty 2.2-nm-thick virtual sections, illustrating the overall arrangement of vesicles within the terminal. Pink spheres are presynaptic vesicles within the cytoplasm; purple spheres are vesicles associated with presynaptic dense projections (shown as large green spheres); blue sphere is a docked vesicle; and red spheres are vesicles fusing with the plasma membrane (see Fig. 6 for further details). Short bridges between neighboring vesicles are shown in blue; bridges connecting vesicles with the plasma membrane are in white. Scale bar $=50 \mathrm{~nm}$ in $\mathrm{A}, \mathrm{B}_{4}$ (applies to $\left.\mathrm{B}_{1}-\mathrm{B}_{4}\right), \mathrm{B}_{5}$. 

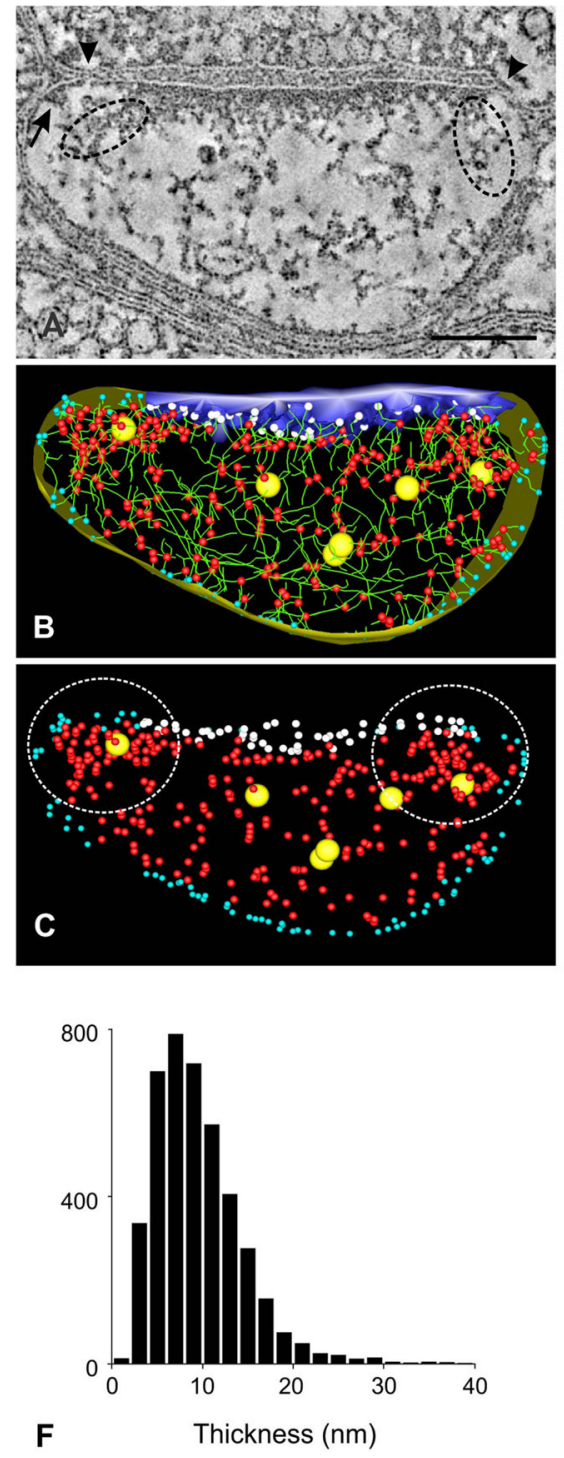
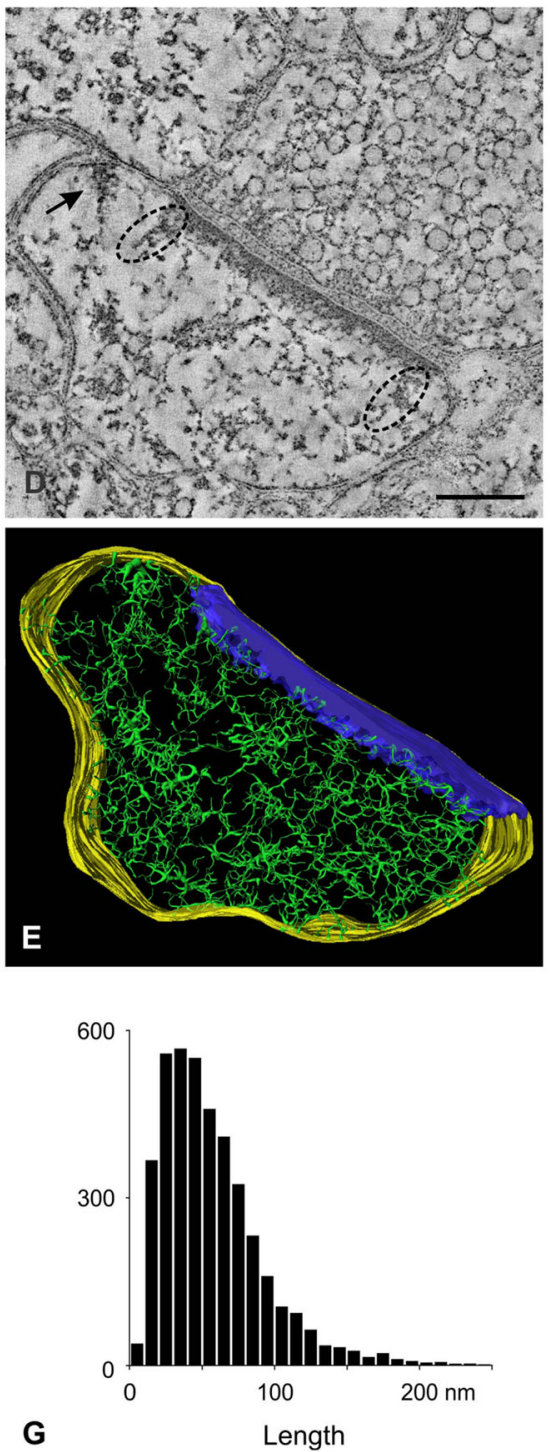

Figure 4.

Postsynaptic spine. A: A tomographic slice through the center of the synapse. Arrowheads at both ends of the synaptic specialization point to a short zone of close contact between preand postsynaptic membranes. Filaments emerging from the postsynaptic density extend into the spine cytoplasm. A dense accumulation of filaments contacts the lateral edge of the PSD (dashed ovals); this accumulation is also associated with an accumulation of electron-dense material lateral to the PSD (arrow at left). The network of internal filaments, manually reconstructed by using IMOD, is shown below. B: Filaments (green lines) exhibit numerous branch points (small red spheres) and a few complex electron-dense junctions (large yellow spheres). Points of contact between filaments and the nonsynaptic plasma membrane are coded as blue circles; contacts with the PSD (indigo) are coded as white circles. C:

Filaments, plasma membrane, and PSD have been removed to emphasize the organization of branching. Branch points are denser near the membrane, especially in a zone close to the edges of the PSD (white dotted circles). D: Tomographic slice of a large axospinous synapse in the stratum radiatum of CA1 hippocampus (from rat R2869, see Materials and Methods); dashed ovals surround accumulations of filaments at the lateral edge of the PSD, and arrow 
points to accumulations of filaments contacting the plasma membrane lateral to the PSD. E: Semiautomated reconstruction of filaments in the spine shown in D, using the "autoskeleton" tool in Amira (Visage Imaging). F: Histogram shows filament thickness (analyzing all 4,164 filaments at least $20 \mathrm{~nm}$ long from both spines). G: Histogram shows filament length (analyzing all 4,091 filaments that were at least $4 \mathrm{~nm}$ thick and not thicker than $20 \mathrm{~nm}$ ). Scale bar $=100 \mathrm{~nm}$ in A,D. 

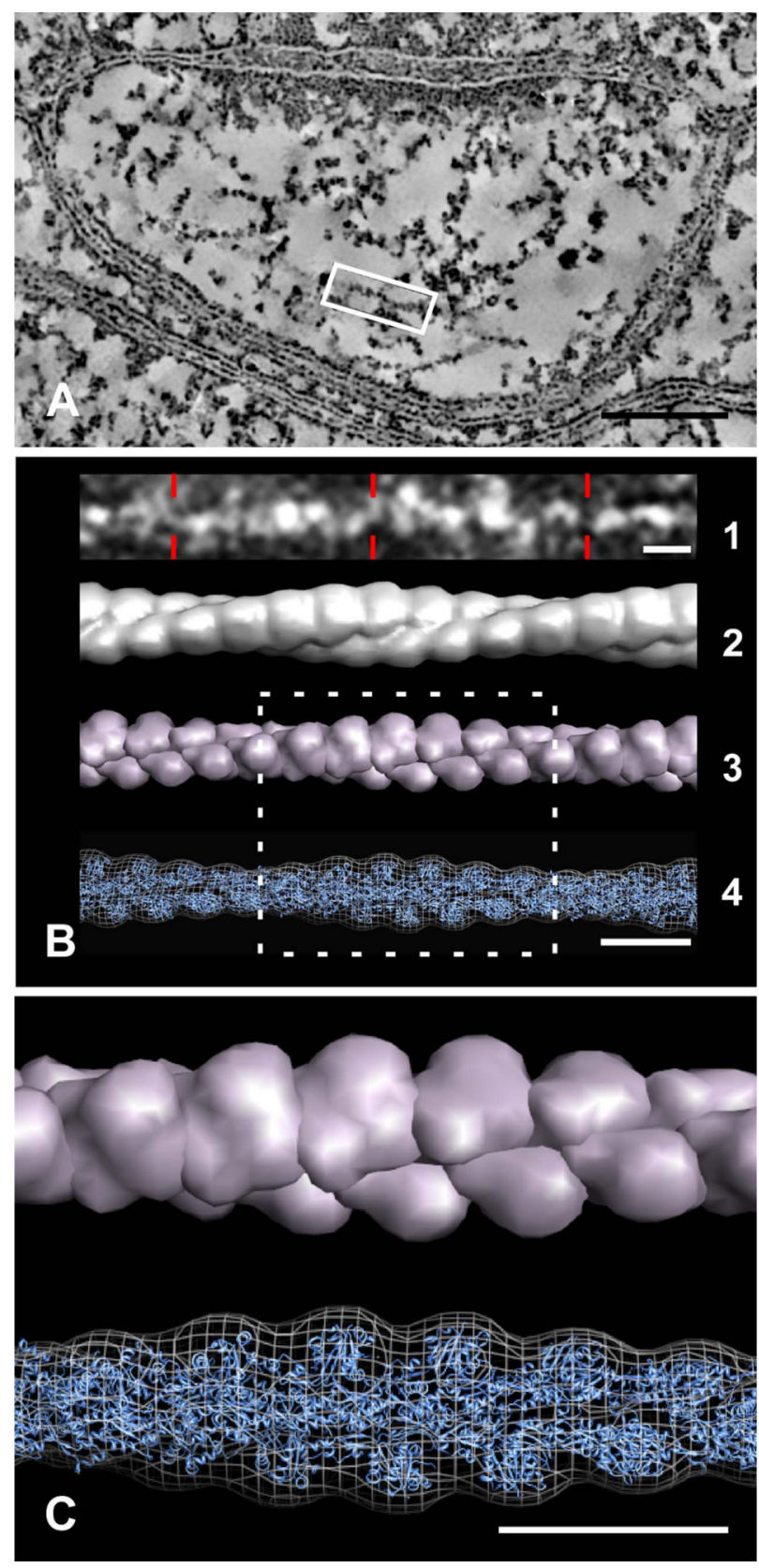

Figure 5.

Relationship of filaments to F-actin. A: A de-noised virtual slice through the postsynaptic spine. A volume containing a long, straight filament is highlighted by the white box. $\mathbf{B}_{\mathbf{1}}$ : A projection of the filament density extracted from the boxed volume. The helical symmetry of the filament can be seen at a qualitative level; several putative actin-binding proteins are attached to the filament. To facilitate comparison with the known structure of F-actin, intensities were inverted so that electron density corresponds to bright intensity values. The extracted filament volume was subjected to a search for helical symmetry parameters, yielding values of $2.8 \mathrm{~nm}$ for helical rise, and -167.4 degrees for angular increment around the axes, very close to the canonical symmetry observed for in vitro actin filaments $(2.7 \mathrm{~nm}$ and -166.7 degrees). $\mathbf{B}_{2}$ : A surface representation of the extracted density after application 
of the deduced helical symmetry. The fact that individual subunits are discernible with sharp edges indicates that the helical symmetry is quite accurate; otherwise the subunits would blur into each other along the filament axis. $\mathbf{B}_{3}$ : A low-resolution representation of an atomic model of a canonical actin filament obtained from high-resolution electron microscopy analysis (Fujii et al., 2010), adjusted for the difference in symmetry parameters. $\mathbf{B}_{4}$ : The fit of this atomic model (blue cartoon representation) into the symmetrized, extracted filament density (white mesh representation of the surface shown in $\mathrm{B}_{2}$ ). $\mathbf{C}$ : Boxed region shown magnified. Fourier shell correlation analysis of the fit indicates that the symmetrized extracted density is equivalent to the atomic actin-filament model up to a resolution of $\sim 4 \mathrm{~nm}$ ( 0.5 cutoff criterion). Scale bar $=100 \mathrm{~nm}$ in A; $10 \mathrm{~nm}$ in B,C. 


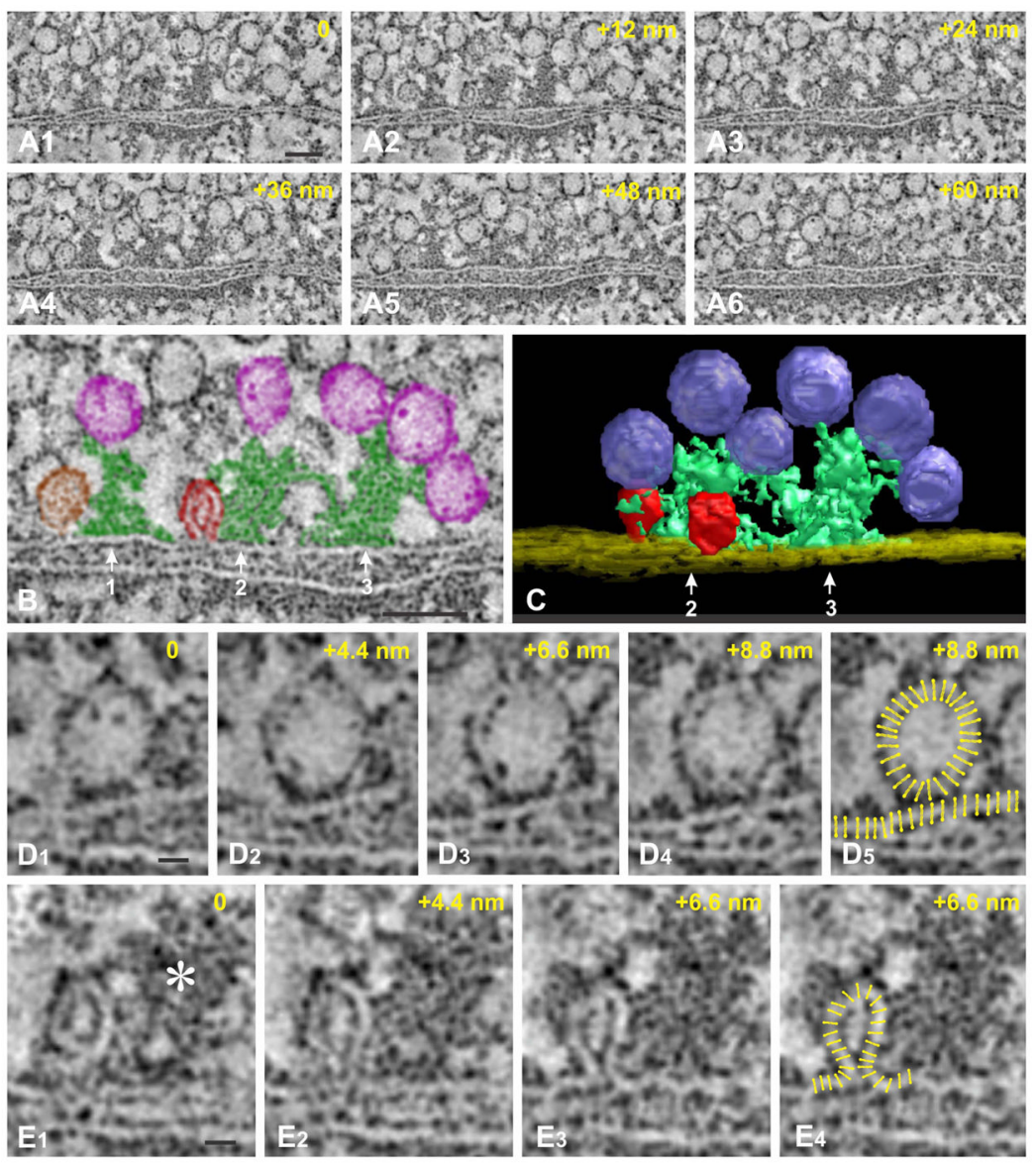

\section{Figure 6.}

Presynaptic active zone. $\mathbf{A}_{\mathbf{1}}-\mathbf{A}_{\mathbf{6}}$ : A stack of six tomographic slices through depth illustrates the active zone and associated dense projections. B: Colorized enlargement of the slice shown in $\mathrm{A}_{3}$ illustrates vesicles in the immediate vicinity of the active zone. Three dense projections are shown in green. Vesicles in the cytoplasm that contact dense projections are shown in purple. A docked vesicle directly contacting the plasma membrane (left, brown) is also associated with a dense projection. A vesicle that has fused with the plasma membrane is seen in the center of the field (red). C: 3D reconstruction illustrates the relationship among dense projections (green), presynaptic vesicles (indigo), and vesicles fused with the plasma membrane (red). $\mathbf{D}_{\mathbf{1}}-\mathbf{D}_{\mathbf{5}}$ : $\mathbf{z}$-series shows a docked vesicle. The region of contact between the docked vesicle and the plasma membrane comprises two separate membranes (symbolized by schematic yellow phospholipid bilayers in $\mathrm{D}_{5}$ ). $\mathbf{E}_{\mathbf{1}}-\mathbf{E}_{\mathbf{4}}$ : $\mathbf{z}$-series shows an exocytotic profile. The fusing vesicle is attached to a dense projection (asterisk in $\mathrm{E}_{1}$ ) via small filaments. Scale bar $=50 \mathrm{~nm}$ in $\mathrm{A}_{1}$ (applies to $\mathrm{A}_{1}-\mathrm{A}_{6}$ ), $\mathrm{B} ; 10 \mathrm{~nm}$ in $\mathrm{D}_{1}$ (applies to $\mathrm{D}_{1}-$ $\mathrm{D}_{5}$ ) and $\mathrm{E}_{1}$ (applies to $\mathrm{E}_{1}-\mathrm{E}_{3}$ ). 


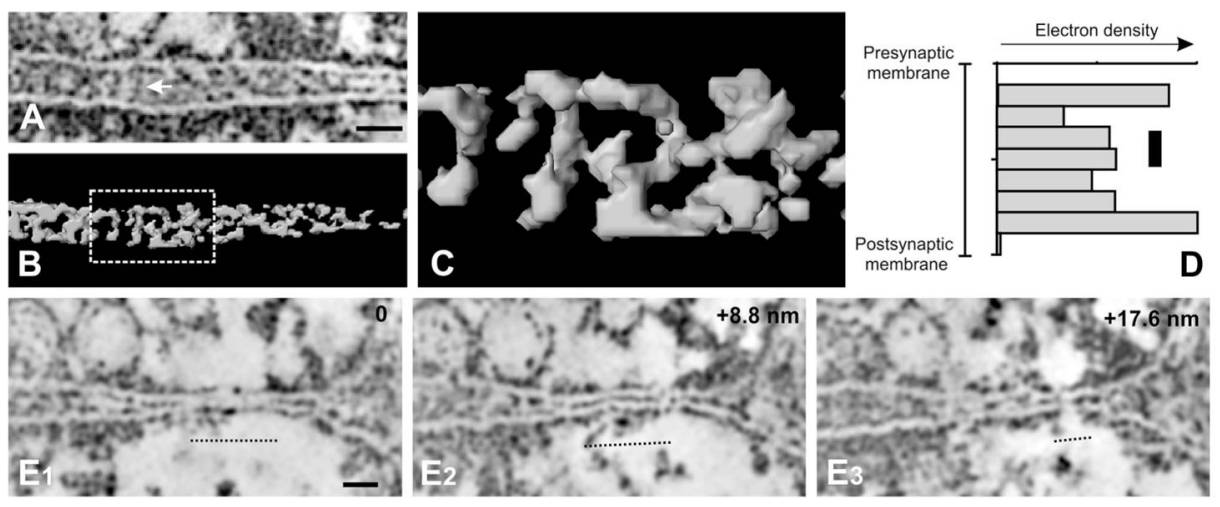

Figure 7.

Synaptic cleft (all panels are from the same tomogram shown in Fig. 2). A: Detail from a tomographic slice, showing the synaptic cleft; note electron-dense "bridges" that span the cleft (white arrow points to an example). B: A 3D reconstruction of the dense material within the synaptic cleft. C: Enlargement of the boxed region in B. D: Histogram of electron density across the cleft. Measurements were taken from a series of rectangular boxes $(6 \times$ $6.6 \mathrm{~nm}$ ) running from pre- to postsynaptic membranes, along the tangential length of the synapse. Pre- and postsynaptic membrane estimates reflect lowered electron densities over the clear center of each membrane; the (variable) cleft distance was partitioned into seven bins between the membranes. The lowest densitometric estimate (associated with the presynaptic membrane) was normalized to zero, and the highest value to 1 arbitrary unit. Highest electron densities were adjacent to the plasma membranes; the modest local maximum of density in the center of the cleft (marked with black rectangle) may correspond to the "intercellular plaque." $\mathbf{E}_{\mathbf{1}}-\mathbf{E}_{\mathbf{3}}$ : Serial tomographic slices show details of a zone of membrane approximation (marked with dotted line) at one end of the synaptic cleft. Scale bar $=25 \mathrm{~nm}$ in $\mathrm{A} ; 20 \mathrm{~nm}$ in $\mathrm{E}_{1}$ (applies to $\mathrm{E}_{1}-\mathrm{E}_{3}$ ). 


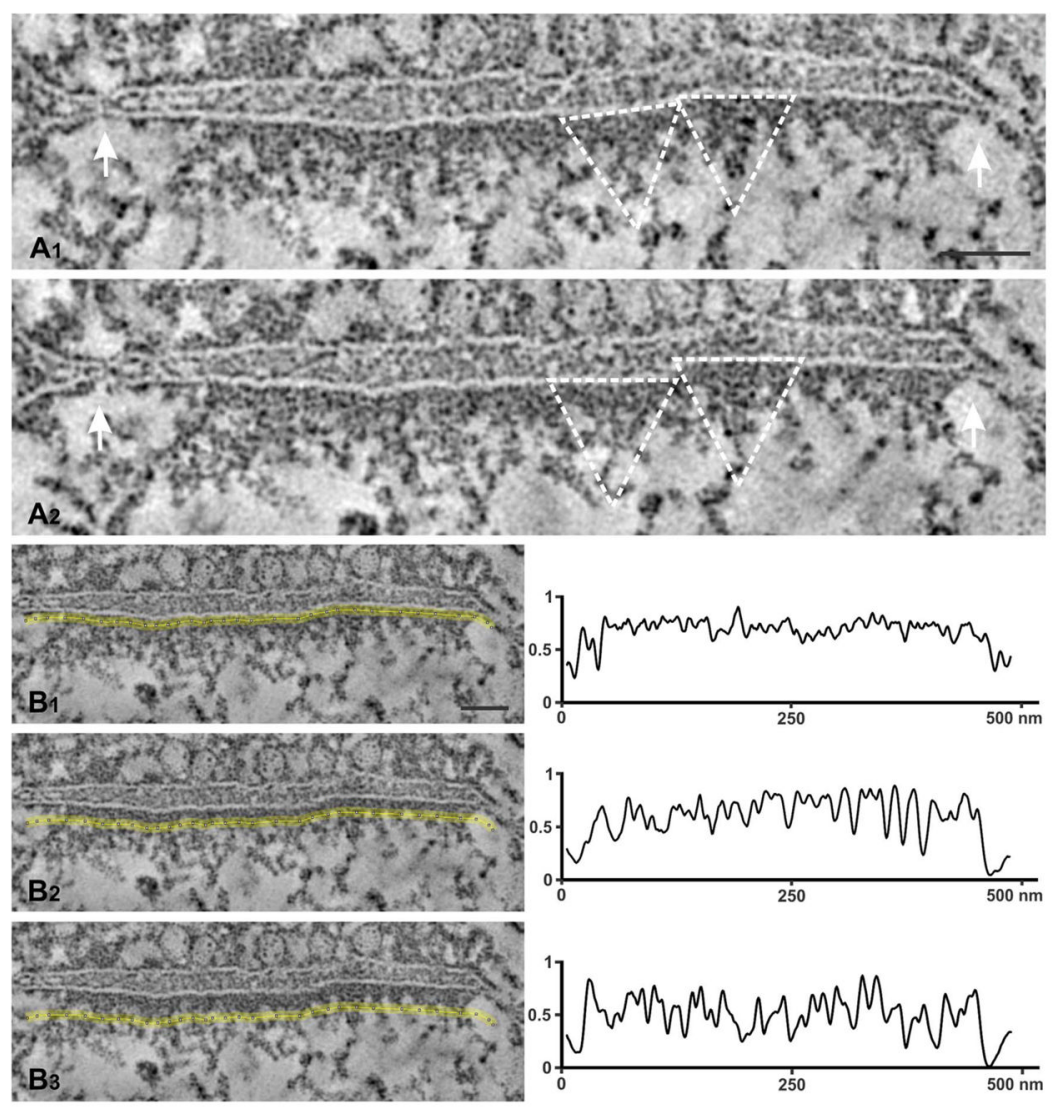

\section{Figure 8.}

Postsynaptic density. $\mathbf{A}_{\mathbf{1}}, \mathbf{A}_{\mathbf{2}}$ : High-magnification view of the postsynaptic specialization, showing two slices ( $6.6 \mathrm{~nm}$ apart). Just inside the postsynaptic membrane, the PSD forms a continuous strip; deeper into the cytoplasm it becomes spiky, breaking into a complex network of filamentous material. The PSD expands at points of contact with cytoplasmic filaments (dotted triangles). Note the dense material filling the synaptic cleft. White arrows point to constrictions between the pre- and postsynaptic membranes, just lateral to the edge of the PSD. $\mathbf{B}_{\mathbf{1}}-\mathbf{B}_{\mathbf{3}}$ : Densitometry (right) quantifies the spatial organization in zones $0-10$, 10-20, and 20-30 nm from the plasma membrane (thick yellow lines on left); densities (measured at each $\mathrm{nm}$ tangentially along the synapse) are presented as moving averages of six bins. The amplitude increases, and spatial frequency decreases, with distance from the membrane. Scale bar $=50 \mathrm{~nm}$ in $A_{1}$ (applies to $A_{1}, A_{2}$ ) and $B_{1}$ (applies to $B_{1}-B_{3}$ ). 